\title{
A Country Perspective in Exploring the links between Hospital Pharmacies and Pharmaceutical Industry: A Case Study Application
}

\author{
Ana Margarida Santos Bravo* and José Crespo de Carvalho
}

ISCTE-IUL- Lisbon University Institute, Lisbon, Portugal

\begin{abstract}
The pharmaceutical industry is one of the firms where the search for quality is very close to compliance. Yet a major paradigm change is occurring in this industry due to the increase of returns and recalls. Hence, in this paper the authors combine the findings of previous literature reviews with a case study approach. Findings from previous literature reviews emerged from the links explored between pharmaceutical drugs quality, reverse logistics and sustainability. With the addition of a case study on a global manufacturing corporation in the area of generic drugs products one step further is introduced: understanding the type of returns companies receive, in particular from hospital pharmacies. With this approach authors are creating a link between two different parties: the application of a quality by design $(\mathrm{QbD})$ risk management approach with the reduction of variability and risk of noncompliance, through the increase of knowledge and value into their products and processes.
\end{abstract}

Keywords: Sustainability; Pharmaceutical industry; Quality by Design (QbD); Value added; Case study

\section{Introduction}

This paper is motivated by the changes that the pharmaceutical industry is undergoing to cope with new challenges of the global economy. Intensive globalization processes, increased competitiveness, fast changing structure of competitors, complex strategic positioning, shrinking pipelines, expiring patents, counterfeit drugs, increased regulatory scrutiny on profits and a fight for global market share are some of the factors giving the pharmaceutical companies new challenges [1-4].

Complex requirements are forcing pharmaceutical manufacturers to adopt more formal business processes and stricter reporting methods [5]. Pharmaceutical companies undergo strong regulations dictated by FDA (Food and Drugs Administration) and EMA (European Medicines Agency), for example. Even small irregularities in products or processes can lead to the elimination of the whole production batches and, in the worst case, lead to enormous civil penalties [6]. Furthermore, as John Avellanet [7] suggests "as long as the industry fails to take a holistic cross-functional view of regulatory compliance, risk management and operational excellence, it will continue to see consent decrease, product recalls and tremendous waste".

The pharmaceutical industry as a whole has traditionally been very profitable. On a global scale, the total size of the global pharmaceutical market has been forecasted to experience growth of 4-6\% exceeding $\$ 825$ billion; the global pharmaceutical market sale is expected to grow at a $4-7 \%$ rate (CAGR) through 2013. Global pharmaceutical market value is expected to expand to $\$ 975+$ billion by 2013 [8]. Besides, total pharmaceutical sales from the top 10 companies accounted for more than $4 \%$ of the total market in 2010. Additionally, the US pharmaceutical market grew by $3.0 \%$ in 2009 to $\$ 300.3$ billion with highest growth in mail services and clinics; the major five Germany, France, Italy Spain and the UK, together accounted for over $60 \%$ of all European pharmaceutical sales in 2009 [9]. Conversely, product recalls in the pharmaceutical industry are becoming extensive and increased radically, according to CNN [10] in 2009 alone, the Food and Drug Administration reported more than 1,984 recalls comparing to 379 from 2008, from that more than 1,000 was from a contract manufacturer; with an estimated $\$ 5$ billion dollars and more than $\$ 700$ million in fines since 2001 and billions more in lost revenues [11,12]. Industry sources have estimated the total of returns cost to be 3 to $6 \%$ of the annual pharmaceutical sales [13]. Product recalls has increased with ranges from 5 to $10 \%$ [14] with an estimated $\$ 5$ billion dollars [11].

The purpose of this paper is to combine the findings of previous literature reviews conducted by the authors associated by the application of a case study. In particular, explore the links between pharmaceutical drugs quality, reverse logistics, and sustainability. The organization of this paper is as follows. After this introductory section, the relevant literature of Pharmaceutical applications these three main topics has been reviewed. The research methodology is followed by results and discussion which discuss the limitations and conclusions of this research.

\section{Literature Review}

\section{Pharmaceutical recalls}

We shall first start to comprehend the process behind drug products approval. No pharmaceutical product can be placed on the market without receiving prior authorization from the regulatory authorities, upon successful completion of a lengthy procedure for evaluating the quality, safety and efficacy of the product. Any change that the company wants to make is always going to be subject to the pervasive requirements of safety, efficacy, quality and cost, making some companies to remain locked into an ancient mindset that says that providing outcomes meet specifications [15]. Nevertheless, this type of approach has been demonstrated fallacious, and to be likely to increase deviations and recalls [16]. In fact, the two most common reasons for the use of reverse logistics in the pharmaceutical industry are: end-of-shelf life products and drug recalls [17].

The evaluation goes primarily against the drug manufacturing

*Corresponding author: Ana Margarida Santos Bravo, Researcher in Pharmaceutical Supply Chains, ISCTE-IUL, Lisbon University Institute, Lisbon, Portugal, Email: margarida.bravo@gmail.com

Received September 03, 2012; Accepted September 25, 2012; Published September 27, 2012

Citation: Bravo AMS, de Carvalho JC (2012) A Country Perspective in Exploring the links between Hospital Pharmacies and Pharmaceutical Industry: A Case Study Application. Pharmaceut Reg Affairs S11:001. doi:10.4172/2167-7689.S11-001

Copyright: (C) 2012 Bravo AMS, et al. This is an open-access article distributed under the terms of the Creative Commons Attribution License, which permits unrestricted use, distribution, and reproduction in any medium, provided the original author and source are credited. 
regulations which are based in the FDA Good Manufacturing Practices (GMP). These regulations have been improved through a management of system approach, in particular with the harmonization between risk analysis and quality systems. These changes have improved the approach to GMP compliance, marketing compliance more comprehensive, integrated, and focused on areas of the greatest impact $[12,18,19]$. Moreover regulators around the world have become more sophisticated in ensuring that drugs are safe and effective $[12,20]$.

Changes made within an operation should be made for a reason with positive business outputs, or else quality improvements would not exist [21]. Then again, in pharmaceuticals, any change that a company wants to make is always going to be subject to the pervasive requirements of safety, efficacy, quality and cost, making some companies to remain locked into an ancient mindset that says that providing outcome meets specifications [15]. However, this type of approach has been demonstrated fallacious, and to be likely to increase deviations and recalls [16], as demonstrated in the introduction section. A recall is defined by the FDA as "when the product is removed from the market or a correction is made to the product because it is either defective or potentially harmful. These recalls sometimes are made by the company which discovers the problem or after FDA raises concerns" [22]. The European Medicines Agency [23] also has a similar definition: "A batch recall is the action of withdrawing a batch from the distribution chain and users. A batch recall may be partial, in that the batch is only withdrawn from selected distributors or users". Product recalls has more than doubled from 5 to $10 \%$ [14] with an estimated 5 billion dollars [17], While there is no value added to the manufacturer as usually CEO's find recalls a failure of their systems quality [24], the fact is, as quickly they react the happier the customer is, actually, a reverse logistics management and cost parameters is found to be generally positive [25].

Table 1 highlights the parallels between the types of recall classification by the FDA (Food and Drug Administration) and EMA (European Medicines Agency), as can be seen high similarities can be identified.

The decision to recall a product may be due to comprise issues related mix-ups, volume, potency, tampering, quality of dosage forms, questioned generic substitutions, labeling defects, lacking therapeutic effects, question formulations, dispenser malfunction and container defects $[22,23,26]$. In the next table, a comparison of the most common incidents registered by both FDA and EMA for the 2011 and 2007 period respectively, can be found.

Although increasing, the recall or removal from the market of pharmaceutical products is not a regular event. When the product involved is a drug which is being dispensed to hospital patients, a product recall has to be carried out quickly and effectively [17,27,28], the replacement with a new one should also be done promptly. Ritchie et al. [17] also state that due to the potential severity of using expired or ineffective drugs, it is critical that pharmaceutical companies get the reverse logistics right from the beginning. Companies must react quickly to problems, as well as clear the supply chain of non-conforming material, so that an appropriate supply chain can be reissued to those waiting for their medications [11].

In summary, no effective medicine is without risk and the benefits of a medicinal product always need to be weighted up against its risks. The challenge to regulators is to find the right balance between timely availability of new medicines and the fact that knowledge on the safety profile is limited at the time of marketing authorization [23]. The next section will discuss the best approaches when dealing with returns of recalled pharmaceutical products.

\section{Pharmaceutical reverse logistic}

Nowadays, pharmaceutical companies are multi-product, multipurpose and multi-site facilities operating in different countries and dealing with a global-wide international clientele. It is very often the case that multi-national companies operate in many geofigureally distributed manufacturing facilities while dealing with an international clientele located in different customer zones. Therefore, the issues related to the trading structure of the company have to be taken into account when deciding on the optimal multi-site investment strategy of the company [28]; therefore, the return of the drug products can be very complex. Returns from the pharmaceutical industry are mainly, end of shelf life drugs and recalls.

When dealing with a recalled product, the same system as a forward logistic cannot be applied, as the reverse supply chain is not a symmetrical image of the forward supply chain, due to the difference in the flows of materials and information demanded by either of them as stated by de la Fuente [29]. Plus, forecasting and planning in reverse logistics also differ from that of the forward supply chain mainly because of the high level of uncertainty concerning returned products and waste materials. Therefore, companies who work in collaboration, become more effective and efficient with the integration within the supply chain.

It is possible to reduce the transportation costs of returned materials by taking possession when delivering newly manufactured products in the area or to the same client. In this case, it is convenient to design transport to facilitate the delivery of the new products with collection of used materials and products to recover; in this case the coexistence between forward and reverse materials is possible, moreover the incorporation of reverse logistics in the existing supply chain means benefits to the manufacturing company, both with regards to quality, by improving customer assistance and product delivers and collection with regard to quantity $[29,30]$.

Moreover, effective recall strategy is, in this sense concerned with minimizing public risk, getting back as many faulty products as possible minimizing cost and inconvenience for the customer and the company (Quesada 2003). In fact the European of Medicines Agency (2011) have been developing the European Risk Management Strategy

\section{EMA}

The defect presents a life threatening or serious risk to health

\begin{tabular}{l|l} 
Class I recall & $\begin{array}{l}\text { A situation in which there is a reasonable probability that the use } \\
\text { of or exposure to a violative product will cause serious adverse } \\
\text { consequences or death }\end{array}$
\end{tabular}

\begin{tabular}{l|l} 
Class I recall & $\begin{array}{l}\text { A situation in which there is a reasonable probability that the use } \\
\text { of or exposure to a violative product will cause serious adverse } \\
\text { consequences or death }\end{array}$
\end{tabular}

$\begin{array}{ll}\text { Class I recall } & \begin{array}{l}\text { A situation in which there is a reasonable probability that the use } \\ \text { of or exposure to a violative product will cause serious adverse } \\ \text { consequences or death }\end{array}\end{array}$

\begin{tabular}{l|l}
\hline Class II recall & $\begin{array}{l}\text { A situation in which use of or exposure to a violative product may } \\
\text { cause temporary or medically reversible adverse health consequences or }\end{array}$
\end{tabular} where the probability of serious adverse consequences is remote

Class III recall A situation in which use of or exposure to a violative product is not likely to cause adverse health consequences
The defect may cause mistreating or harm to the patient or animal, but is not life threatening or serious

The defect is unlikely to cause harm to the patient, and the recall is carried out for other reasons such as non-compliance with the market authorization or specification

Table 1: Recall classification comparison. 
(ERMS) whose main goal is to provide a more proactive conduct of pharmacovigilance by putting in place measures that allow the early detection, assessment, minimization and communication of risks of drugs throughout their lifecycle.

The firm's ability to develop competitive advantage depends on several factors; the ability to display and make use of value adding capabilities is one of them. The greater and more unique the value added, the more reliant on that firm other parties are likely to be. According to Womack and Jones "value can only be defined by the ultimate customer"; nevertheless, the lean approach considers three rules for determining if an activity is considered value added: 1) the customer must be willing to pay for the activity; 2) the activity must transform the product service in some way; 3 ) the activity must be done correctly the first time [31]. Therefore, regarding our question above, there is no value added for the product itself, no value to the customer but costs to the supply chain [11].

On the other hand, the added value could be attributed to the improvement of customer service leading to the increase in customer retaining and sales, as the goal of almost every business is to lock customers so that they will not move to another supplier. In addition, reduces pharmacy costs, maximizing manufacturer credit benefits and/ or reduce cycle times [25,32]. Moreover, quick and efficient handling of returned products can also be critical in sustaining relationships and creating repeat purchases. Reverse logistics is of strategic importance as it provides companies the opportunity to differentiate themselves, builds consumer confidence in the company brands, and positively influences customer satisfaction and loyalty, increasing profits enhancing brand image and product after market [17,25,27,33].

To sum up, product recalls are generally viewed unfavorably by investors, and a failure to their systems quality [24,26]. In the same line, product returns can present a significant challenge for manufacturing firms whose primary objective is usually geared towards producing and selling products to customers. The impact of returns is sometimes disregarded, or at least, not well understood in most firms. In others, returns are often considered just a necessary cost-of-doing business [34], like the pharmaceutical. During a drug product recall the company must rely on the distributors or wholesalers distribution information [11], in particular customer service, depot repair, endof-life manufacturing, IT management, recycling, refurbishing/ screening, replacement management, returns authorization, spare parts management, transportation, warehousing and warranty management [35]. In addition, reverse logistics leads to an increase of customer satisfaction and recovery of value; as well as reduces pharmacy costs, maximizing manufacturer credit benefits and/or reduce cycle times [25,34].

Competitive and economic pressures continue to have a significant impact on the segment, an increasing number of companies have begun to view the reverse logistics chain as a process that may be used to manage costs and drive additional revenues through the management and tracking of the return [32]. The majority of authors agree that reverse logistics is of strategic managerial opportunity to build competitive advantage [35]. It increases customer satisfaction, gives better visibility, and more efficient operations through improved space utilization, labor planning and inventory controls. By using resources to improve logistics related processes the entire service quality of the firm may be escalated in the eyes of the customer. Moreover, the firm may then be viewed as easy to do business with and responsive. In addition, a quality based strategy for competitive advantage focus on strategic resources and continuous quality improvement, thus sustainable competitive advantage is powered by a strategy focused on increased quality of product or service and continuous improvement may lead to efficient competition. Moreover, extending the value chain to include recovery operations, such as recycling, reuse and remanufacturing adds an additional level of complexity to value chain design and a new set of strategies and operational issues.

\section{Pharmaceutical sustainability}

Pharmaceutical companies are being accounted as more responsible towards sustainability. As the industry experiences an increasing pressure from regulation markets in the demand for more sustainable products, the need to become more sustainable increases, and the responsibility of its activities should be expanded from the production site to the whole product chain [36,37].

Pharmaceutical companies are using the Global Reporting Initiative (GRI) as a way to implement and measure their level of sustainability. The GRI guidelines have been developed and revised through a process involving various stakeholders [38]. As part of the standard sustainability report, the GRI guidelines suggest the use of indicators to measure an organizations performance in environmental, social and economic areas. They list over 100 possible indicators for companies to use, both generally applicable and organization-specific, such as total water used and recycle material. The GRI guidelines act as an educational vehicle and promote corporate social responsibility reporting for integrating environmental, social and economic aspects, and promote transparency and improved dialogue between business and stakeholders [39]. In addition, due to the fact that financial and social criteria are crucial parts, these truly differentiate 'sustainability' reporting from straight environmental reporting [40].

The sustainability Report from 2009 for the pharmaceutical industry revealed the PSI scores (Pacific Sustainability Index (PSI) which uses two systemic questionnaires: one base questionnaire for reports across sectors and a sector specific questionnaire for companies within the same sector) for 26 largest pharmaceutical companies in the world. The findings of the reports include: 1) companies in the pharmaceuticals sector place varying importance on sustainability reporting transparency; 2) As in many sectors, environmental performance was the most underreported section. Fewer than half of the sector's companies reported using environmental accounting, green purchasing and chemistry, or concern for biodiversity, and fewer than $60 \%$ of the companies mentioned climate change; 3 ) Across the sector, social reporting scores were generally better than scores for environmental reporting; 4) the pharmaceutical sector certainly should continue to address social issues on which it has a direct effect, such as health disparities, as well as the important environmental challenges all corporations face; 5) Many pharmaceutical companies have room for extensive improvements in their sustainability reporting, although there are some leaders in the sector setting a 'stellar' example. Ten of the 26 companies in the sample were GRI reporters, all of which finished in the top half of the reports 'Overall Grade' list [41].

In summary, expectations on safety and health are increasingly, more and more due to globalization. Firms in the pharmaceutical industry are now expected to be responsible to economic, societal and environmental needs. Moreover; environmental protection and sustainability cannot only be used to improve the public perception of the manufacturing efficiency as costs for input and output resources [41]. The adoption of sustainable practices helps business to distinguish them from competition through the reduction of unnecessary risks, generation of waste, increasing efficiency of materials and energy, innovating by new and environmental friendly products and services as well as gaining operating licenses from local communities [42], and 
as soon as any harm is discovered and brought to the stakeholders attention, its root causes are identified and properly rectified [43]. This type of approach leads to the increase in business performance and profitability, sustaining their activities longer [37].

\section{Introduction to Pharma Co}

Phama Co. develops manufacturers and market generic and inlicensed pharmaceutical products within three core business. The operations span 49 countries and focus on key therapeutic areas such as anti-infectives, cardiovascular, alimentary tract and central nervous system. The injectable business markets 120 branded and non-branded injectable products in 215 dosage, strengths and forms, including 7 in-licensed products. Why Pharma Co. was selected? The 2010 revenue was $\$ 731 \mathrm{~m}$; by region: $61 \%$ MENA, $28 \%$ from the US and for Europe and the rest of the world accounts for $10.9 \%$. Selecting it by segment, $23.9 \%$ are generics; $21.5 \%$ injectable drug products and $54 \%$ are branded. It has more than 400 products marketed in 2010. And an operating cash flows over $\$ 140.0 \mathrm{~m}$. It is the second largest generic injectable supplier by volume in the US with combined market share of more than $15 \%$. Comparing to this introductory section one can expect that it is a good fit of the current pharmaceutical industry scenario. Towards the understanding of their major complaints, semistructure interviews were applied not only to the company in question, in the main injectable manufacturing and distribution sites, but also to several hospital pharmacies in different countries of action. With this approach it is expected to link both parties in the application of a quality by design (QbD) risk management approach as well as reduce variability and risk of noncompliance. With this approach a more sustainable pharmaceutical supply chain is expected to flourish, reducing waste, an increase of corporate social responsibility.

\section{Research Methodology}

In studying the dynamic, complex and context-dependent problems, it is imperative that researchers explore wider methodology options. Theory-building research in operation management often requires in-depth analysis of data from real-world situations because the knowledge base has not yet sufficiently developed to allow the use of hypothetic-deductive approaches. In this study, both quantitative and qualitative approaches have been used. There were also other issues as time and resource constrains and access to data that needed to be taken into account.

Case study research can provide rich insights into complex phenomena, leading towards an understanding of their deeper structures within naturalistic settings [44]. The contribution of these insights, particularly in the early exploratory phase, to theory building is indispensable. However, the findings of case-study research often challenged on the basis of their reliance on retrospective accounts (internal validity), individual bias (construct validity and reliability), and the idiosyncrasy (external validity) of findings [44]. By comparison the later versions of the grounded theory approach have some inherent strength that can effectively negate most of these limitations, but are faced with the difficulties associated with the operationalization of the methodology. For example, entering the field with no preconceived ideas, achieving theoretical saturation and the level of creativity and theoretical sensitivity expected of the researcher - have all been challenges for many researchers. However, in terms of overall credibility, the grounded theory approach is strongly guarded by its relatively structured and rigorous process of data collection, analysis and theory generation. As such, this study decided of a combined "grounded theory - case study" approach, informed by the school of thought, for studying the link between pharmaceutical industry and hospital concerns towards quality issues. The methodological approach adopted is consistent with the objective of the study.

One organization with 22 manufacturing plants in several global regions, like US, Europe, Middle East and North Africa, and operating over 49 countries was selected. As such, the case was designed to include several countries of action; hospitals were chosen by their size, as well as having a link to this company in some way. The main selected product category chosen was injectable drug products which are only dispensed in hospital pharmacies; therefore, from the 4 countries where these plants are located, Portugal was selected as the pilot site for the study. After evaluation of the available data in the company, three regions were nominated for interviews: US, representing 51\%, Europe accounting for $21 \%$ and $23 \%$ from MENA of the injectable revenue by region.

In Figure 1, dark blue are the regions where Pharma Co. Operates, green are the sites where injectable drug products are manufactured.

Product complaints were evaluated from 2006 until 2011 and patterns were identified and grouped in categories. The selected categories underlined the two main regulatory agencies in the world: the USFDA and EMA. The drug product quality defects reported by the two agencies are shown in Table 2 , in this table the identified groups of Pharma Co. are also included and a correlation can be done.

The principal method of data collection was semi-structured interviews, drawing participants from different hierarchical levels of the organization was backed up by a limited document analysis. The key players for the semi-structure interviews were selected in a three step process. First, the analysis of the five years of complaints received by the pilot site and the identification of the key issues rose. Second, the identification from which main distribution countries those came from. Third, from where the complaints were reported.

Interviews were conducted with management staff representing quality assurance, regulatory affairs, and quality compliance, from the industry side and procurement from hospitals. Each interview took about 45 to 90 min duration. Where allowed, all interviews were recorded and transcribed into text. The action of interviewing, compiling and analyzing data took around 3 months to accomplish. Participant-observer study also took place during the data collection. The use of multiple sources of evidence in case studies allows an investigator to address a broader range of historical and behavioral issues, but most importantly the developing of covering lines of inquiry, a process of triangulation and corroboration [43].

\section{Results and Discussion}

The first approach to the study was to understand the type of issues this industry is facing, with regards to quality and compliance. Therefore, complaints from 5 years were evaluated, in order to better understand what type and from where, complaints were being received.

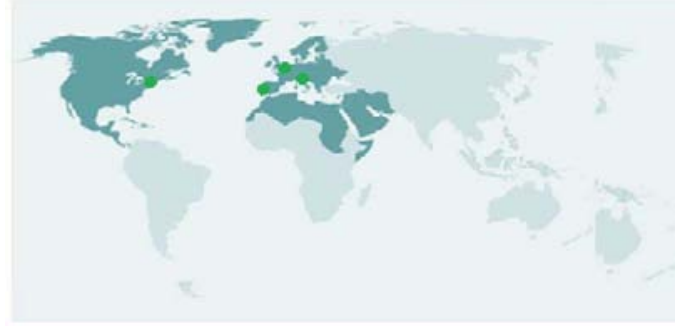

Figure 1: Pharma Co. operation sites and injectable manufacturing plants 


\begin{tabular}{|c|c|c|c|c|c|}
\hline \multicolumn{2}{|l|}{ CDER $^{1}$} & \multicolumn{2}{|l|}{ EMA $^{1}$} & \multicolumn{2}{|l|}{ Pharma Co. } \\
\hline Category & Incidence(\%) & Category & Incidence(\%) & Category & Incidence(\%) \\
\hline Product Defects & \multirow{2}{*}{$\begin{array}{l}27 \% \\
24 \%\end{array}$} & \multirow{2}{*}{$\begin{array}{l}\text { Product Defects } \\
\text { Deviation from Manufacturing authorization }\end{array}$} & $15 \%$ & Container closure & $6 \%$ \\
\hline Formulation/Substitution & & & $15 \%$ & Formulation(color/ dissolution/particles) & $34 \%$ \\
\hline Labeling & $13 \%$ & Product information literature & $23 \%$ & Labeling/packaging & $11 \%$ \\
\hline Packaging & $6 \%$ & Packaging Material & $14 \%$ & Delivery & $2 \%$ \\
\hline Fill Problem & $5 \%$ & Ancillary materials & $14 \%$ & Fill volume & $4 \%$ \\
\hline Delivery & $13 \%$ & OOS & $2 \%$ & ADE & $11 \%$ \\
\hline Other & $12 \%$ & GMP findings & $7 \%$ & Other & $<1 \%$ \\
\hline
\end{tabular}

${ }^{1}$ Source: CDER (FDA), 2011 \& EMA, 2007

Table 2: Reported Drug Quality Defects and correlation with Pharma Co.

The total of complaints accounts for $100 \%$, the amounts are calculated on a percentage basis. From the data analysis as seen in Figure 2, around $80 \%$ of the reported complaints came from hospitals, and about $30 \%$ were found at third party warehouses.

From depth analysis of the reported complaints the following was noted, formulation issues were the most addressed, here are also included problems regarding color of the reconstitution solution, dissolution, formation of crystals and particles. These so called problems after investigations were found to be described in the product literature as well as expected chemical reactions of the drug product. Adverse reactions were also reported, the same way a full investigation was performed of these complaints and it was noticed that all reactions were listed in the drug product literature. Therefore, the number of these types of complaints could be reduced with the increase of customer service support. The third most common complaint came from issues related to the container-closure systems; where according to the root cause was attributed to manufacturing issues in most cases; as shown in Figure 3, also refer to Table 2.

It was also observed an increase of registered complaints $45 \%$ in 2011 compared to the $4 \%$ in 2007 these results were obtained from the total of the complaints. In the author's opinion, the increase of patient awareness could also be responsible for the higher number of complaints in recent years. Nevertheless, it could also be observed that the increase of complaints is also related to the increase in business development (Figure 4).

The final step for semi structured interview selection was the identification of the markets where the majority of complaints were reported. It was noted the following: the United States have the highest percentage of complaints with $51 \%$, followed by Jordan (12\%) and Germany (11\%), refer to Figure 5. These results are consistent with the market share where the company operates, as referred in the introductory section, United States, Europe and MENA region respectively.

After the first quantitative assessment and confirming that the main complaints came from hospitals as mentioned in the introductory section. Semi-structure interviews were performed on the company in question, in four main sites (US, Germany and Jordan, Portugal was used as the pilot site where the injectable products were manufactured), these represent the leading operational regions: US, Europe and MENA regions; characterized by the higher revenue. In summary, the model for interviews was identified as follow. The squares represent the industry sites evaluated; where the circles represent the hospital pharmacies.

The interviews took place in both industry and hospitals. The target people were management staff from Regulatory Affairs, Quality Compliance and Quality Unit. In the different countries of action selected, the key players were procurement. The goal is to in validate the issues encountered and link both parties. With this approach it is expected to relate both sides in the application of a Quality-byDesign (QbD), which is a "systematic, scientific, risk-based, holistic and proactive approach to pharmaceutical development that begins with predefined objective and emphases product and processes understanding and process control" [45]; approach associated with risk management to reduce variability and risk of compliance.

The findings are presented in the form of textual descriptions and exploratory accounts aided by data displays, leading towards the linkage between the two parties.

The first question posed was related to the state of compliance in the countries where the majority of complaints were registered (US, Jordan and Germany). Similar answers were gathered, the state of compliance is outlined in detail by regulatory entities such as the FDA or EMA, also noted by the increase in controls; enforcement acts and vigilance from these regulatory bodies, which is also in line with the comments received by hospital pharmacies (Figure 6).

With regards to the type of complaints reported such as labeling and packaging, lack of potency and transportation problems, just to name a few, all parties considered it a trend. It was also pointed out that transportation issues will continue to happen as companies do not hold the transportation carriers accountable for their service. The US respondent also suggested that Customer service levels should be reviewed, service agreements should be in place and audits should be conducted. This comment is in line to the author's opinion, where if customer service improves its knowledge a several number of complaints registered by the manufacturing site will actually disappear.

For the drug product efficacy situation, it is reported as a subjective matter as other factors interfere with the cause, as people react differently to medicines; however, the increase of consumer awareness is the most probable action. Hospitals were also consistent in their response towards the main concerns of injectable drug products, as listed in Table 2. Moreover, the validity of such complaints was also subject to consideration, and all interviewees considered them valid. Nevertheless, the efficacy/potency issue is once again subject to subjectivity as drugs wok differently for people; just because someone does not receive the expected result, it does not mean that the drug lacks efficiency.

One of the main links that we are trying to accomplish is with regards to the implementation of a risk management and $\mathrm{QbD}$ approach in order to reduce variability, non-compliance issues and increase sustainability in the pharmaceutical supply chain. Although not fully implemented in the company in question at the several manufacturing sites around the world it is currently being evaluated and the first steps towards its implementation are taking place. These approaches emphasize product and process understanding and process control. Increasing the robustness of the process, reduction of variation 


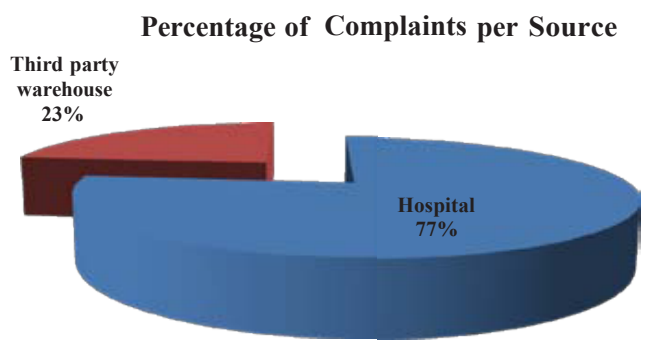

Figure 2: Percentage of complaints where the problem was reported from

\section{Percentage of type of complaints received}

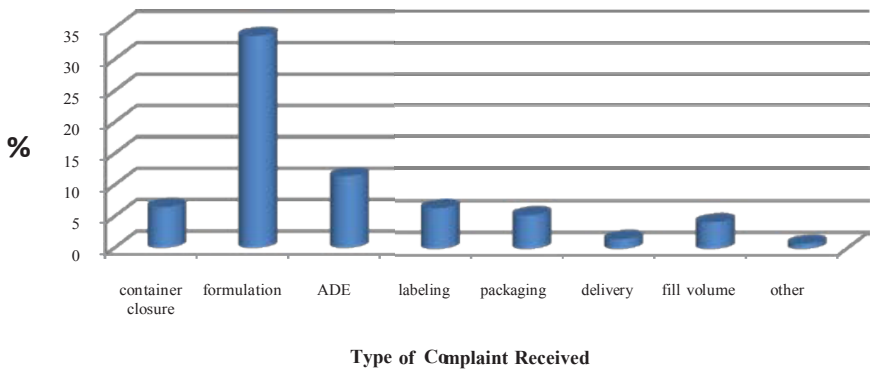

Figure 3: Percentage of type of complaints received.

Correlation between \% of Complaints vs. Volume of Sales

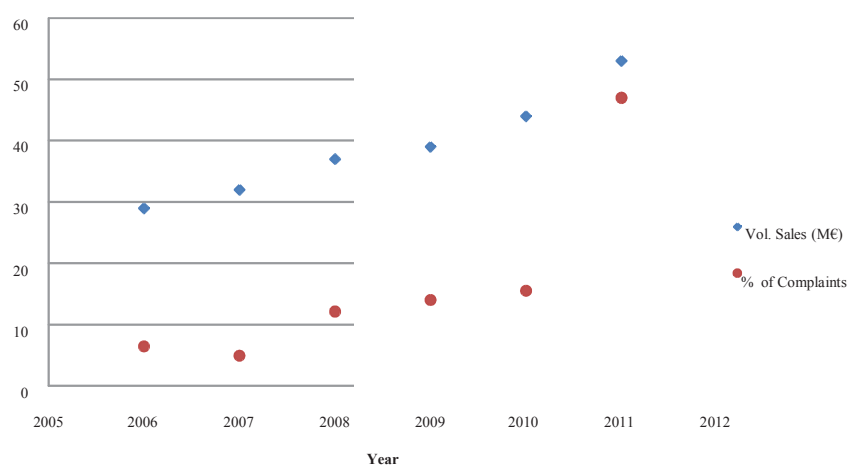

Figure 4: Percentage of received complaints per year.

will also reduce the risk; and consequently reduction of complaints and recalls is expected, this comment was transversal in all countries of action $[46,47]$.

It is known that the main returns that the pharmaceutical industry faces are due to end of shelf products and recalls; the first one is promptly replaced by manufacturers. The second situation was found to be mainly due to field alert actions and Out-of-Specification (OOS) issues during shelf life studies; au contrary of what was hypothesized being due to regulatory agencies enforcement acts or complaints. Again, it is expected with the adoption of the new paradigm the decrease of the field alert and recalls as well as the decrease of costs to remove the non-conformity product of the market, in this subject hospitals mentioned that companies react very quickly when situations like this happen, replacing with a new batch leading to a satisfied customer and added value.

One of the last questions posed to our interviewees was the understanding of what in their opinion are the focal influences that are affecting the pharmaceutical industry these days mainly due to the increase of global supply chain. Here some differences were noted; the US respondents only mentioned quality and compliance; whereas Europe and MENA are also concerned with counterfeiting drugs coming mainly from India and China. The counterfeiting and fraud scandals that hit the industry in the recent years, also consistent with our introductory section and literature review made the agencies increase the controls on pharmaceutical industry. The MENA region also mentioned the multiplicity of suppliers posing an important weight on product quality, this is due to the fact that for example, two or more active pharmaceutical ingredients (API) suppliers can be approved by the agencies, although these may have individual characteristics complying with the regulatory guidelines, the final product must have the same quality and characteristics. This may be a challenge. On the other hand hospitals are more concerned with the profit margins of the industry as well as their apprehension in the noninvestment on investigation leading to a decrease of product quality. Nevertheless, in the author's opinion, this case may not be expected as the industry is increasing the understanding of their process towards the improvement of product quality by the design towards a more sustainable of the supply chain.

\section{Conclusion}

The goal of this paper was understand the reason behind the increase of pharmaceutical recalls, through a case study application. The change in paradigm is obliging companies to gain more knowledge of their process better from the research and development phase (R\&D), by designing drug products, generics or branded, beyond compliance

Correlation between \% of Complaints vs. Volume of Sales

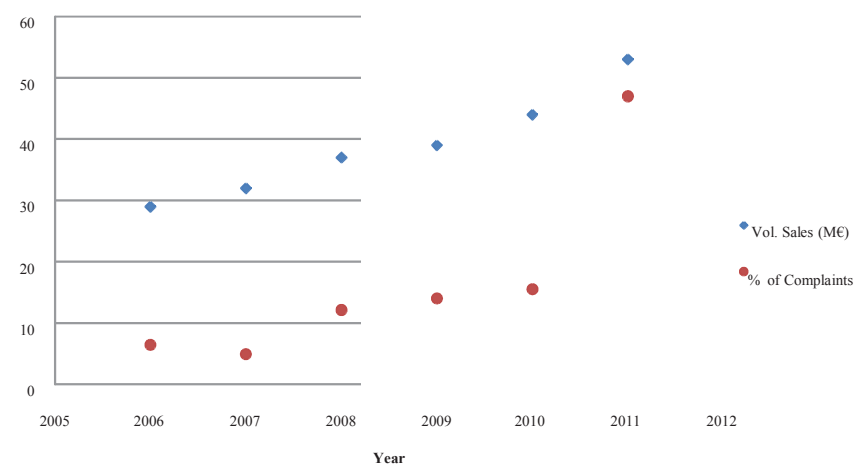

Figure 5: Percentage of received complaints per country of action.

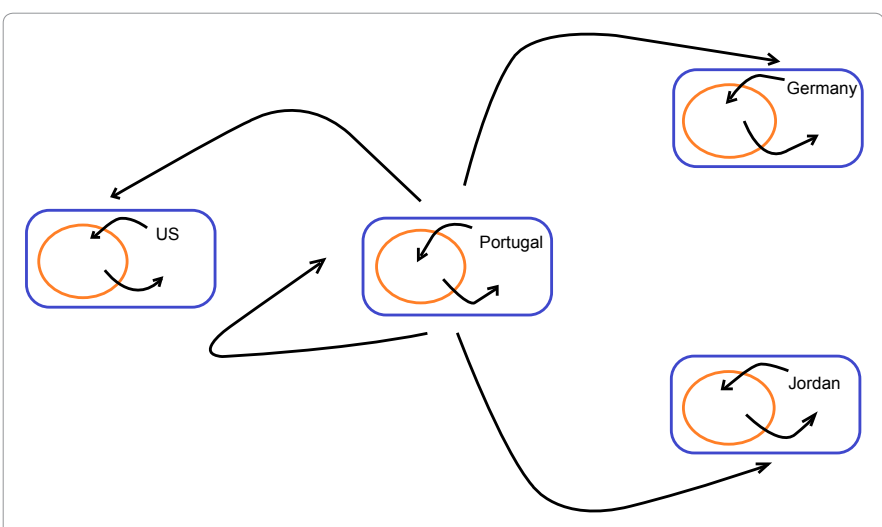

Figure 6: Model for semi-structure interviews. 
to regulations until the end user, in this particular case the hospital patient. As well as adding more value to their products. This could be observed from the exposed analysis.

With the application of a Quality-by-Design (QbD) Risk Management approach it is expected a substantial decrease in drug product recalls and pharmaceutical returns. Leading to a reduction of wasted revenues in reverse logistic operations and an improvement of more sustainable pharmaceutical supply chains as well as the increase of value added to all parties involved, keeping up with other industries.

One curious fact with regards to the semi-structure interviews approach was that hospitals were the least responsive party compared to the company. Hospitals will be in fact the most beneficiary party with this approach and the change in paradigm. At the company, when first approached $100 \%$ accepted the challenge, while in hospitals only after several and persistent attempts only a few interviews were accomplished.

From this study a country comparison can be done with regards to the health system in place in each of the selected countries of this study. Moreover, a cause-effect, action-reaction type relationship (ARA methodology Activities-Relations-Actions) can be applied which is the next step of our research project, identifying the patters and action taking with some causal understanding (to make meaning of the observed patterns).

\section{References}

1. Papageorgiou LG, Rotstein GE, Shah N (2001) Strategic supply chain optimization for the pharmaceutical industries. Ind Eng Chem Res 40: 275-286.

2. (2009) CBR Pharma Insights: The New Pharmaceutical Sales Force - Key Trends Shaping Future Sales Strategies. Reuters online.

3. Almor T, Tarba S, Benjamin H (2009) Unmasking integration challenges: The case of Biogal's acquisition by Teva Pharmaceutical Industries. International Studies of Management and Challenges 39: 32-52.

4. Edwards A (2010) Manufacturing the future. Integrated collaboration between CMOs and Sponsors.

5. Souza D, Danase J, Constatinou D (2005) Business Efficiency and Regulatory Compliance.

6. Gronauer T, Scherrer-Rathje M, Friedli T (2009) A reference framework to sustainably implement operational excellence in the pharmaceutical industry. EUROMA, Sweden.

7. Avellanet $\mathrm{J}(2010)$ Holistic quality and compliance: a guide for, and from, the C-level by John Avellanet.

8. IMS Health (2010).

9. Key market forecasts and growth opportunities (4th Edition) (2010) Pharmaceutical Market Trends, 2010-2014.

10. CNNMoney (2010) Drug Recalls Surge.

11. Kumar S, Dieveney E, Dieveney A (2009) Reverse logistic process control measures for the pharmaceutical industry supply chain. International Journal of Productivity and Performance Management. 58: 188-204

12. D'souza A, Keeling D, Phillips R (2007) Improving quality in pharma manufacturing. The McKinsey Quarterly.

13. Hunter ST, Droege M, Marsh WA, Droege WL (2005) CE: Effectively managing pharmaceutical returns and waste. Drug Topics 149: 36.

14. Abboud L, Hensley S (2003) New prescription for drug makers: update the plants. The Wall Street Journal.

15. McConnell J, Nunnally BK, McGarvey B (2009) Variation - Past, Present, and Future. Journal of Validation Technology 37-42.

16. Mahboubian-Jones G (2009) Pharmaceutical Quality and Lessons from Toyota: Thoughts from Gawayne Mahboubian-Jones.

17. Ritchie L, Burnes B, Whittle P, Hey R (2000) The benefits of reverse logistics: the case of Manchester Royal Infirmary Pharmacy. Supply Chain Management 5: 226-234.

18. Pluta P, Poska R (2010) Compliance by Design (CbD) and Compliance Master Plan (CMP)-An Organized Approach to Compliance. Journal of GXP Compliance 14: 73-82

19. International Conference on Harmonization

20. LevisAA, Papageorgiou LG (2004) A hierarchical solution approach for multi-site capacity planning under uncertainty in the pharmaceutical industry Computers and Chemical Engineering 28: 707-725.

21. Dale B (2003) Managing Quality. (4thedn), Blackwell Publishing, Oxford.

22. Food and Drug Administration (2007) CDER Facts and Figuresle.

23. European Medicines Agency (2007) An Analysis of Quality Product Defects in Centralized Procedure.

24. Krumwiede D, Sheu C (2002) A model for reverse logistics entry by third-party providers. Omega 30: 325-333.

25. Fassoula ED (2005) Reverse logistics as a means of reducing the cost of quality. Total Quality Management \& Business Excellence 16: 631-643.

26. Cheah ET, Chan WL, Chieng CLL (2007) The corporate social responsibility of pharmaceutical product recalls: An empirical examination of US and UK markets. J Bus Ethics 76 : 427-449.

27. Autry CW (2005) Formalization of reverse logistics programs: A strategy for managing Liberalized returns. International Marketing Management 34: 749757.

28. Bowersox DJ, Closs DJ (1996) Logistical management: The integrated supply chain process. McGraw-Hill International Editions, London.

29. de la Fuente MV, Ros L, Cardós M (2008) Integrating Forward and Reverse Supply Chains: Application to a Metal-Mechanic Company. Internationa Journal of Production Economics 111: 782-792.

30. Stock JR (1998) Development and Implementation of Reverse Logistics Programs. Council of Logistics Management.

31. http://www.pharmaqbd.com

32. Biederman D (2010) Speeding Up, in Reverse. Journal of Commerce, New York.

33. Howard I, Humby S (2008) Embedding Corporate Responsibility into Supply: A Snapshot of Progress. European Management 26: 166-174.

34. Mollenkopf DA, Russo I, Frankel R (2011) Creating Value through Returns Management: Exploring the market-Operations Interface. Journal of Operations Management 5: 391-403.

35. Kumar S, Putnam V (2008) Cradle to cradle: reverse logistics strategies and opportunities across three industry sectors. International Journal of Production Economics 115: 305-315

36. Jorgensen TH (2008) Towards more Sustainable Management Systems: through Life Cycle Management and Integration. Journal of Cleaner Production 16: $1071-1080$

37. Linton JD, Klassen R, Jayaraman V (2007) Sustainable Supply Chains: An Introduction. Journal of Operations Management.

38. GRI (2011)

39. Veleva V, Ellenbecker M (2001) Indicators of Sustainable Production: Framework and Methodology. J Clean Prod 9: 519-549.

40. Morhardt JE, Baird S, Freeman K (2002) Scoring corporate environmental and sustainability reports using GRI 2000, iso 14031 and other criteria. Corporate Social Responsibility and Environmental Management 9: 215-233.

41. Stegemann S (2010) Better by design

42. Székely F, Knirsch M (2005) Responsible Leadership and Corporate Socia Responsibility: Metrics for Sustainable Performance. European Management Journal 23: 628-647.

43. Campbell J (2007) Why Would Corporations Behave in Socially Responsible Ways? An Institutional Theory of Corporate Social Responsibility. Academy of Management Review 32: 946-967.

44. Yin RK (1994) Case Study Research: Design and Methods. SAGE Publications London. 
Citation: Bravo AMS, de Carvalho JC (2012) A Country Perspective in Exploring the links between Hospital Pharmacies and Pharmaceutical Industry: A Case Study Application. Pharmaceut Reg Affairs S11:001. doi:10.4172/2167-7689.S11-001

45. Yu LX (2008) Pharmaceutical quality by Design: Product and Process Development, Understanding, and Control. Pharmaceutical Research 25: 781791

46. Sartori G (2011) Reverse logistics role in securing pharmaceutical supply chain. Reverse Logistics Magazine.
47. Porter M (1998) Competitive Advantage: Creating and Sustaining Superior Performance. The Free Press, New York. 